Check for updates

Cite this: RSC Adv., 2018, 8, 25546

\title{
One-step green approach for functional printing and finishing of textiles using silver and gold NPs
}

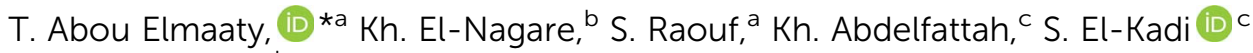 \\ and E. Abdelaziz ${ }^{d}$
}

In this study, we present a successful simple method for printing and finishing of polyester and cotton fabrics using gold and silver nanoparticles (Au-NPs and Ag-NPs, respectively) as stable, fast colorants and functional components. The surface plasmon resonance (SPR) bands of the colloidal gold and silver NPs were observed at $\lambda_{\max } 520 \mathrm{~nm}$ and $450 \mathrm{~nm}$, respectively, indicating the presence of spherical Au-NPs and Ag-NPs, which was further confirmed by TEM analysis. The printed samples were subjected to SEM, XRD and EDX analyses. The SEM images and EDX spectra unequivocally confirmed the existence of embedded NPs on the fabric surfaces. Both the cotton and polyester samples possessed excellent color fastness, as indicated from the color fastness test. The functional properties of the printed fabrics indicated that the incorporation of Au-NPs and Ag-NPs into the fabrics simultaneously imparted multifunctional properties such as stable brilliant colors, highly durable antimicrobial activity and very good UV-protection properties.

Received 24th March 2018 Accepted 2nd July 2018

DOI: 10.1039/c8ra02573h

rsc.li/rsc-advances methods for their preparation ${ }^{\mathbf{4 - 1 0}}$ and to enhance the functions of the textiles such as flame retarding ability, hydrophobicity, self-cleaning, and resistance to wrinkles as well as antistatic, antimicrobial and UV-protective properties. ${ }^{11-13}$ In addition, these NPs are endowed with unique localized surface plasmon resonance properties (SPR) and thus exhibit brilliant and different colors. With such excellent properties, novel shades of elegant hues and excellent multifunctional activities on different textile materials have been achieved. ${ }^{\mathbf{1 4 , 1 5}}$

Nevertheless, many dyes are not stable under irradiation of sunlight and have low resistance to washing and rubbing, causing color fading. Metal NPs are different from traditional dyes: it is not the chromophore of traditional dyes but the shape and size of NPs that define the colors. This property makes all the colors stable towards UV light, and they do not change provided that there is no change in the particle size through the growth or reduction of discrete nanoparticles or agglomeration. ${ }^{16,17}$ According to the previous literatures, most printing methods are based on the utilization of pigments or dyes as colorants incorporated with metal NPs as finishing agents to produce multifunctional printed textiles. ${ }^{\mathbf{1 8 - 2 1}}$ However, these methods consume a lot of chemicals, time, and energy.

Recently, several attempts have been carried out to use gold and silver NPs to dye fabrics with colors and simultaneously implement functionality to the dyed fabric, e.g., antibacterial activity ${ }^{22,23}$ and/or UV-protection. ${ }^{24}$ Based on the literature, the incorporation of gold and silver NPs into fabric or fiber materials is applied using three different procedures: impregnation of fabrics in the prepared metal NP colloidal solution, ${ }^{25-27}$ preparing metal NPs in situ in fabrics, ${ }^{\mathbf{1 4 , 2 8 - 3 2}}$ and synthesizing 
polymer-NP composites followed by a spinning process to form colored fibers. ${ }^{33}$

To the best of our knowledge, textile printing with metal nanoparticles as a colorant has not been reported to date. Therefore, the main task of this study is to investigate a novel, simple, one-step, green approach for printing natural and synthetic fabrics, namely, cotton and polyester fabrics using gold and silver NPs as stable and fast colorants. This is an environmentally friendly solution for the current harmful printing, coloration and finishing processes.

\section{Experimental}

\subsection{Materials}

Scoured and bleached plain weave polyester $\left(100 \%, 109 \mathrm{~g} \mathrm{~m}^{-2}\right)$ and mill-scoured, bleached knitted cotton $\left(200 \mathrm{~g} \mathrm{~m}^{-2}\right)$ fabrics were used.

Sera ${ }^{\circledR}$ Binder M-CPB liquid (acrylate-based copolymer, anionic, Clariant) and Sera ${ }^{\circledR}$ print M-CPK thickener 160 EG liquid (synthetic thickening agent based on ammonium polyacrylate, Clariant) were used.

Chloroauric acid $\left(\mathrm{HAuCl}_{4} \cdot 3 \mathrm{H}_{2} \mathrm{O}\right.$, Sigma-Aldrich $)$ was purchased from Skyspring Nanomaterials, Inc. USA.

All other chemicals used during this study such as $\mathrm{AgNO}_{3}$ (Sigma) and tri-sodium citrate $\mathrm{Na}_{3} \mathrm{C}_{6} \mathrm{H}_{5} \mathrm{O}_{7} \cdot 2 \mathrm{H}_{2} \mathrm{O}(99.5 \%)$ were of commercial grade.

\subsection{Methods}

2.2.1. Preparation of gold nanoparticles (Au-NPs). Au-NPs were prepared by adding $5 \mathrm{ml}$ of $5 \mathrm{mM}$ of gold(III) chloride hydrate, $\mathrm{HAuCl}_{4}\left(2 \mathrm{mg} \mathrm{ml}{ }^{-1}\right)$, to $85 \mathrm{ml}$ of filtered deionized water, which was then refluxed in a $250 \mathrm{ml}$ flask over a hot plate and heated to boiling point. Five milliliters of $25 \mathrm{mM}$ sodium citrate solution was quickly added to the boiling solution and stirred for 30 min until the color became wine-red. ${ }^{34}$

\subsubsection{Preparation of silver nanoparticles (Ag-NPs)}

2.2.2.1. Preparation of extract. Pluchea dioscoridis leaves were collected from Damietta, Egypt. The leaves were cleaned well and washed using tap water followed by distilled water. The clean leaves were dried for a week at room temperature and then was ground to powder form. Five $g$ of the leaf powder was introduced into boiling distilled water $(200 \mathrm{ml})$ in an appropriate flask for $5 \mathrm{~min}$. Then, the mixture was filtered, and the filtrate was stored at $40{ }^{\circ} \mathrm{C}$ for further use.

2.2.2.2. Synthesis of silver nanoparticles (Ag-NPs). Various volumes (1 and $12 \mathrm{ml}$ ) of Pluchea dioscoridis extracts (Pd) were placed in $100 \mathrm{~mL}$ Erlenmeyer flasks. Then, $45 \mathrm{ml} \mathrm{AgNO}{ }_{3}$ with different concentrations (1-5 $\mathrm{mM}$ ) was titrated drop by drop in each flask for $10 \mathrm{~min}$. The formation of Ag-NPs was confirmed by the change in colour from colorless to reddish-brown. ${ }^{35}$

2.2.3. Printing paste method. The formulation for aqueous printing using the flat screen technique is shown in Table 1

Printed fabric samples were then simultaneously dried and fixed in a high temperature steamer at $150{ }^{\circ} \mathrm{C}$ for $4 \mathrm{~min}$ followed by washing using $2 \mathrm{~g} \mathrm{l}^{-1}$ non-ionic detergent at a liquor ratio of 1 : 50 at $60{ }^{\circ} \mathrm{C}$ for $10 \mathrm{~min}$.
Table 1 Formulation for aqueous printing using flat screen technique

\begin{tabular}{ll}
$\begin{array}{l}\text { Printing } \\
\text { paste components }\end{array}$ & $\mathrm{g} \mathrm{kg}^{-1}$ paste \\
\hline Thickener & 20 \\
Binder & 100 \\
Nano-material & 20 \\
Water & 840 \\
Total & 1000
\end{tabular}

\subsection{Characterization}

2.3.1. TEM analysis. Transmission electron microscopy (TEM) analysis of the cell-free extract was used to determine the size and morphology of the synthesized nanoparticles using a JOEL model 1200EX election microscope operated at an accelerating voltage of $120 \mathrm{kV}$. The specimen for TEM measurement was prepared by dissolving a drop of colloidal solution on a 400-mesh copper grid coated with an amorphous carbon film and evaporating the solvent in air at room temperature.

2.3.2. UV-vis spectroscopy. UV-vis spectroscopy on Shimadzu UV-2450 was used to qualitatively confirm the presence of Au-NPs and Ag-NPs in the reaction medium. The reaction solutions exhibited intense absorption peaks due to surface plasmon resonance (SPR).

2.3.3. SEM and EDX analysis. Scanning electron microscopy (SEM) images and EDX analysis of the printed metal NP samples were obtained using JEOL JSM-6510LB Japan-Tokyo.

2.3.4. X-ray diffraction (XRD). The crystalline natures of the prepared NPs and printed samples were determined using an Xray diffractometer (XRD) (Bruker D8 ADVANCE, Karlsruhe, Germany).

\subsection{Testing}

2.4.1. Colorimetric analysis. The colorimetric parameters $L^{*}$ (lightness), $a^{*}$ (redness-greenness), $b^{*}$ (yellowness-blueness) and color strength $(K / S)$ of the printed cotton and polyester fabrics were measured using a Konica Minolta CM-3600 d spectrophotometer (Minolta, Tokyo, Japan).

2.4.2. Color fastness. The color fastness properties of the obtained prints to washing, rubbing and light were determined according to the AATCC Test Methods (61-1972), (8-1972), and (16A-1972), respectively.

2.4.3. Durability test. Durability to washing was evaluated according to the AATCC Test Method 61(2A)-1996 after 10 washing cycles.

\subsection{Functional properties of metal NP-printed fabrics}

2.5.1. Antimicrobial activity. The antimicrobial activities against $\mathrm{G}+\mathrm{ve}$ bacteria (Staphylococcus aureus and Bacillus cereus) and G-ve bacteria (Escherichia coli and Candida utilis) were evaluated qualitatively according to the AATCC Test Method (147-1988) and were expressed as the zone of growth inhibition (mm). 
2.5.2. UV-protection properties. UV-protection functionality, expressed as UV-protection factor (UPF), was evaluated according to AS/NZS 4399 : 1996, and protection was rated as good, very good or excellent if the UPF values ranged from 15 to 24,25 to 39 , or above 40 , respectively.

\section{Results and discussion}

The main task of the current study is to obtain a facile novel one step green procedure for printing cotton and polyester fabrics using colloidal gold (Au-NPs) and silver (Ag-NPs) as stable and fast colorants to attain multifunctional prints based on nanomaterials. The results obtained and the appropriate discussions are presented below.

\subsection{Characterization of the synthesized nanoparticles}

3.1.1. TEM analysis. The morphology, shape, and size of the synthesized Au-NPs and Ag-NPs were characterized using transmission electron microscopy. Fig. 1 shows the TEM images of Au-NPs and Ag-NPs. The size of the NPs was determined by measuring the diameter of the entire particle in the TEM images. As depicted from Fig. 1a, the average diameter of the gold NPs was found to range between 13 and $20 \mathrm{~nm}$ in a monodispersed state due to the negative charge of the citrate ions, which repel each other. ${ }^{36}$ Moreover, the TEM image demonstrates the spherical shape of the synthesized Au-NPs. Fig. 1b presents the TEM image of the synthesized Ag-NPs. It was clear that the particles exhibited a spherical-like shape and were uniformly distributed and well dispersed. The average size of the prepared Ag-NPs was in the range of 15-25 nm, which indicated sufficient homogeneity and well dispersion of the silver particles. Ag-NPs were observed to be sufficiently close to each other, which attributed to the lack of reducing or stabilizing agent in the solution. ${ }^{37}$

The size of numerous particles were measured using the TEM images, and histograms providing different size distributions of the well-dispersed suspensions of $\mathrm{Au}$ and $\mathrm{Ag}$ NPs were given in Fig. 1c and d, respectively. The width of the Au-NP bins was $3 \mathrm{~nm}$, as illustrated in Fig. 1c, and they were centered at 12, 15, 18 and $21 \mathrm{~nm}$. Au-NPs around $18 \mathrm{~nm}$ in size exhibited the highest percentage value (47.79\%) in comparison with other $\mathrm{Au}$ NPs present in the colloid. From Fig. 1d, for Ag-NPs, the bins of the histogram were $5 \mathrm{~nm}$ wide, and they were centered at 5,10 , 15,20 and $25 \mathrm{~nm}$. The majority of particles (30-33\%) were located at around $5 \mathrm{~nm}$, which may be the main reason for the high antimicrobial activity of Ag-NPs.

3.1.2. UV-vis spectroscopy. UV-vis spectroscopy is one of the most common techniques used to verify the formation and stability of metal NPs in aqueous solutions. Gold and silver NPs
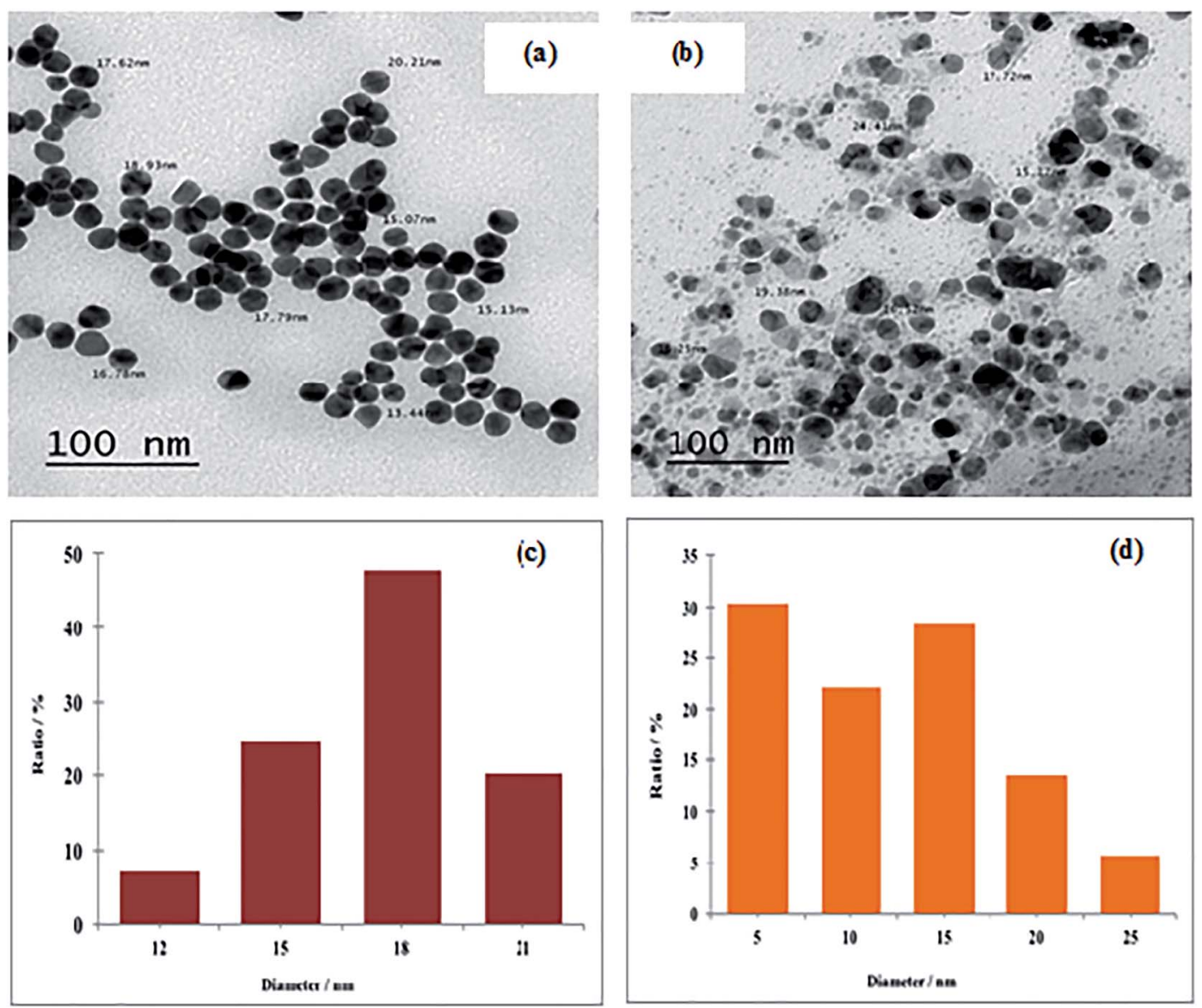

Fig. 1 TEM images and size distribution histograms of the synthesized metal NPs: (a and c) Au NPs and (b and d) Ag-NPs. 
have been reported to exhibit different colors in aqueous solutions, depending on their size and intensity in relation to their SPR. ${ }^{38}$ The synthesis of stable Au-NPs was conducted through a reduction process using sodium citrate as the reductant and stabilizer. The interest in this synthetic process is due to the resultant versatile citrate layer on the Au-NP surface, which allowed easy multifunctionalization of the obtained particles. ${ }^{39}$

Fig. 2a shows the UV-vis spectrum of the synthesized Au-NPs, and a maximum absorbance peak of the colloidal Au-NPs occurred at about $520 \mathrm{~nm}$. Generally, Au-NPs displayed a single absorption peak in the visible range between 510 and $550 \mathrm{~nm}$ due to its SPR and exhibited heavy absorption of visible light at $520 \mathrm{~nm}$. This was resulted in a brilliant wine-red color for the gold NPs, which varied according to its size and shape. Alaqad et $a .^{40}$ also observed the absorbance spectrum of Au-NPs at around $520 \mathrm{~nm}$, whereas $\mathrm{HAuCl}_{4}$ did not exhibit any absorbance at the same wavelength.

Fig. $2 \mathrm{~b}$ shows the UV-vis spectrum of the synthesized Ag-NPs; it can be clarified that due to the yellowish color of the colloidal $\mathrm{Ag}$-NPs, the maximum absorption peak was at about $450 \mathrm{~nm}$, which was specific to SPR of spherical Ag-NPs. ${ }^{37}$ This result confirmed the proposed formation according to transmission electron microscopy (TEM). Both the UV-vis absorption (Fig. 2b) and TEM (Fig. 1b) results verified that the yellow color of the colloidal Ag-NPs was a result of the presence of spherical AgNPs.

The observed broad peak illustrates that the synthesized AgNPs were different in size and shape, which was in agreement with the TEM analysis (Fig. 1b). Krishnaraj et al. ${ }^{41}$ reported that a single SPR band indicates spherical nanoparticles, whereas two or more SPR bands indicate anisotropic particles. Furthermore, it was observed that another strong UV absorption peak appeared at about $350 \mathrm{~nm}$, which may be due to the residual plant extract used in the synthesis of Ag-NPs or trace iron impurities, which appeared in the ppm level. ${ }^{42}$

3.1.3. SEM and EDX analysis. Fig. 3 shows the SEM images of the polyester and cotton fabrics printed with Au-NPs and AgNPs. It is clear that there is a change in their surface morphology with the deposition of NPs onto their surfaces. Furthermore, the EDX spectra confirmed the existence of metal nanoparticles (Au-NPs and Ag-NPs) on the fabric surfaces. Therefore, the results indicated that Ag-NPs and Au-NPs were successfully distributed on all the examined printed fabric surfaces.

3.1.4. X-ray diffraction (XRD). The formation of metal NPs was also confirmed by X-ray diffraction (XRD) analysis. The XRD patterns of the synthesized Au-NPs in Fig. 4 revealed that $\mathrm{Au}$ is crystalline with a face-centered cubic (fcc) structure corresponding to clear peaks at 38.25 (111), 44.46 (200), 64.64 (220), and 77.20 (311), respectively. The obtained results were in good agreement with the data for standard gold in JCPDS file no. 040784. On the other hand, the XRD patterns of the synthesized Ag-NPs in Fig. 4 exhibited a face centered cubic structure according to the four reflection peaks at $2 \theta$ values of $38.11^{\circ}$, $44.29^{\circ}, 64.45^{\circ}$ and $77.39^{\circ}$, which were indexed to the (111), (200), (220), and (311) crystal planes, respectively (JCPDS card no. 89-3722). The XRD results provided strong evidence for the presence of gold and silver particles and thus confirmed the UVvis and TEM results. ${ }^{\mathbf{4 3 , 4 4}}$

\subsection{Color measurements}

The color of printed fabrics is of key significance since it may impact the product demand and consumer inclination. To investigate the color properties of nano-printed fabric surfaces, their colorimetric data were measured for Au-NP- and Ag-NPprinted fabrics using the CIELAB system in terms of $L^{*}, a^{*}$, and $b^{*}$ to study the effect of gold and silver NPs as new colorants for cotton and polyester fabrics. The color coordinates are listed in Tables 2 and 3. After printing fabrics using colloidal solutions of Au-NPs and Ag-NPs, red-wine and yellow printed polyester and cotton fabrics were obtained with different shades and very good homogeneity, as shown in Fig. 5.

Table 2 shows the colorimetric data for the printed fabrics using Au-NPs and Ag-NPs. At low concentrations of NPs, the colors of the printed cotton and polyester fabrics were light redwine for Au-NPs and light-yellow for Ag-NPs, as shown by the low positive $a^{*}$ and $b^{*}$ values. With an increase in the concentration of Au-NPs, the positive $a^{*}$ value progressively increased giving a reddish tone to the printed fabrics. The color of the Ag-
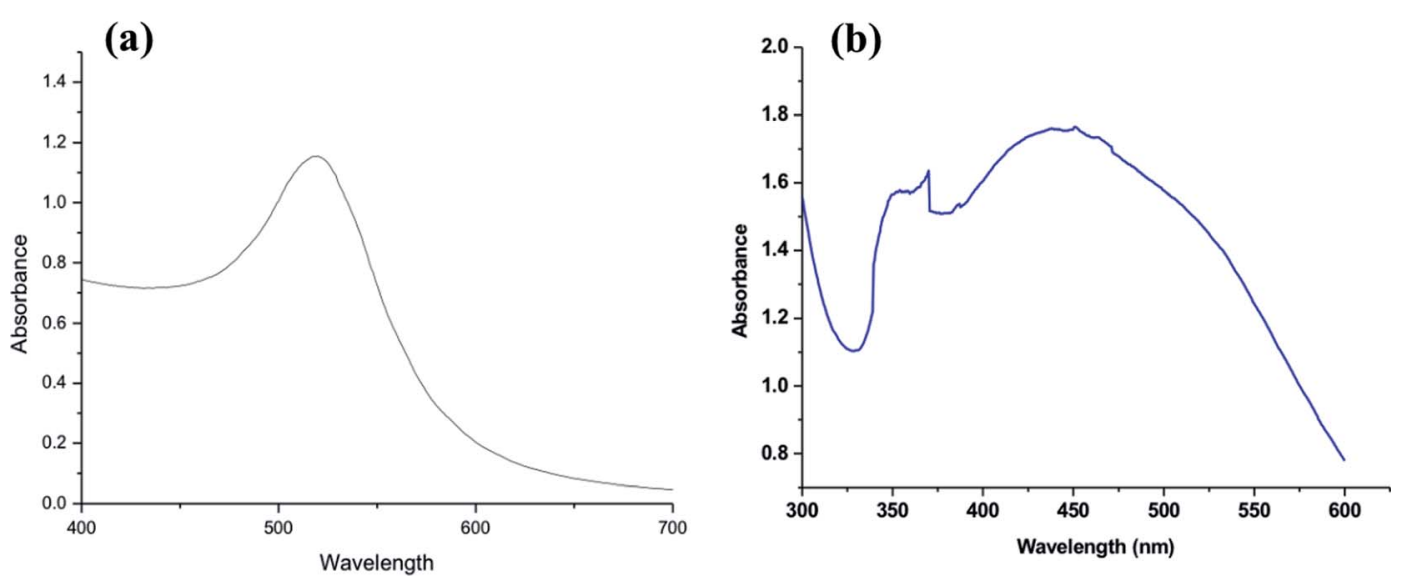

Fig. 2 UV-visible absorption spectra of the synthesized NPs: (a) Au-NPs and (b) Ag-NPs. 

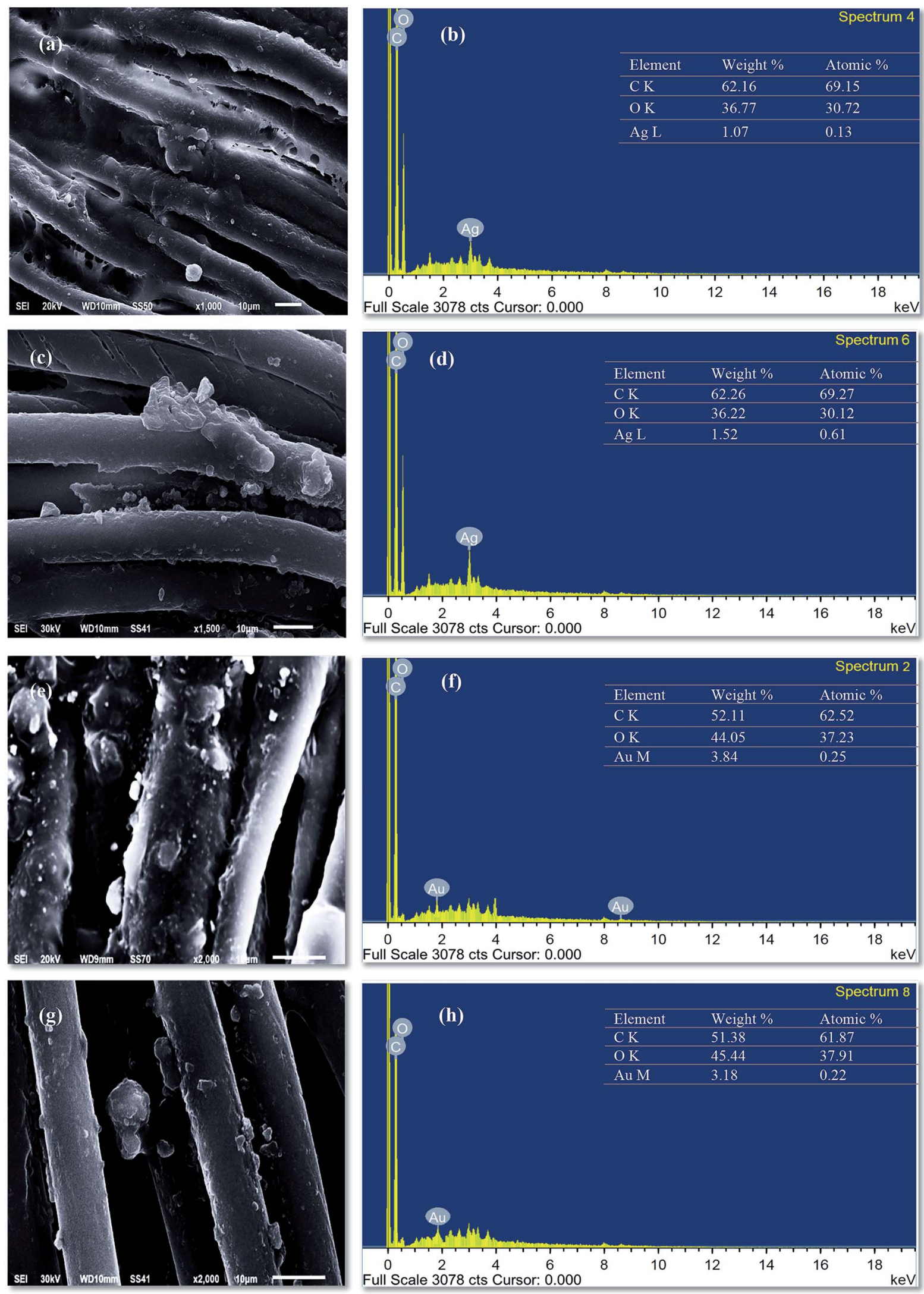

Fig. 3 SEM images and EDX spectra of the metal NP-printed samples: Ag-NPs cotton (a and b) and polyester (c and d). Au-NPs cotton (e and f) and polyester ( $\mathrm{g}$ and $\mathrm{h})$. 

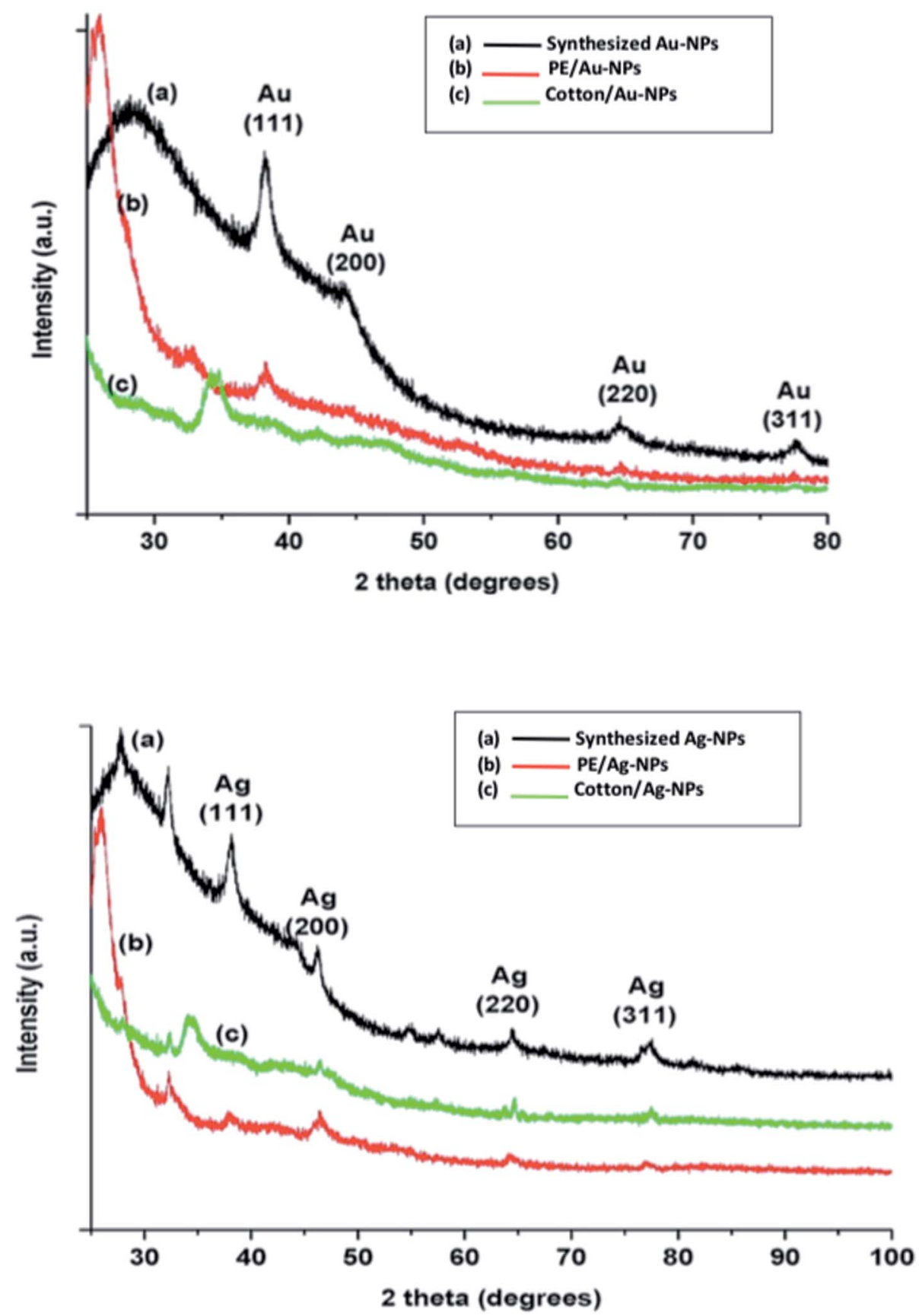

Fig. 4 XRD patterns of the synthesized metal NPs and printed fabrics.

Table 2 Colour characteristics and K/S values of the Au-NP-printed fabrics

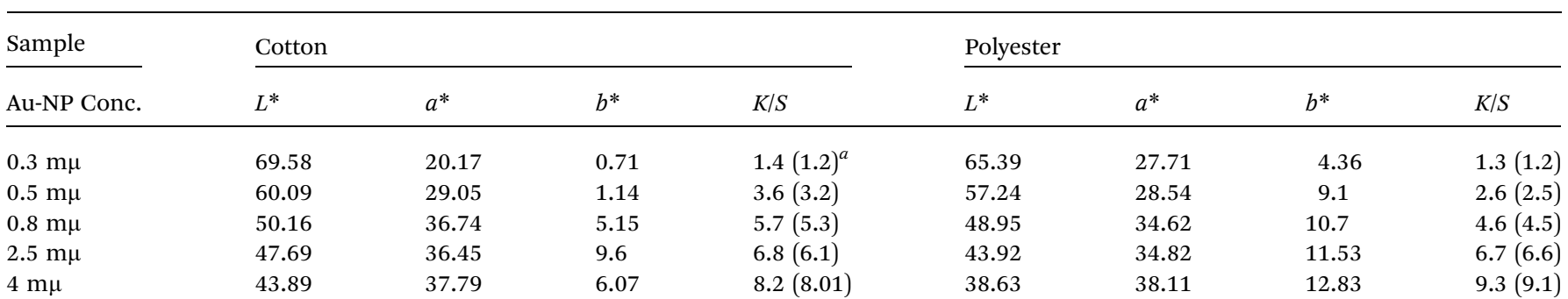

${ }^{a}$ Values in parentheses indicate $K / S$ after 10 washing cycles. 
Table 3 Colour characteristics and $K / S$ values of the Ag-NP-printed fabrics

\begin{tabular}{|c|c|c|c|c|c|c|c|c|}
\hline \multirow{2}{*}{$\frac{\text { Sample }}{\text { Ag-NP Conc. }}$} & \multicolumn{4}{|c|}{ Cotton } & \multicolumn{4}{|c|}{ Polyester } \\
\hline & $L^{*}$ & $a^{*}$ & $b^{*}$ & $K / S$ & $L^{*}$ & $a^{*}$ & $b^{*}$ & $K / S$ \\
\hline $5 \mathrm{~m} \mu$ & 85.72 & 6.52 & 6.69 & $2.7(2.5)^{a}$ & 81.87 & 4.68 & 20.76 & $1.2(1.2)$ \\
\hline $6 \mathrm{~m} \mu$ & 82.91 & 4.54 & 21.54 & $4.6(4.6)$ & 69.55 & 13.93 & 33.6 & $2.5(2.4)$ \\
\hline $7 \mathrm{~m} \mu$ & 78.94 & 5.95 & 30.67 & $5.7(5.6)$ & 61.97 & 18.8 & 37.38 & $3.7(3.5)$ \\
\hline $8 \mathrm{~m} \mu$ & 75.7 & 11.1 & 39.74 & $7.4(7.2)$ & 60.35 & 23.43 & 46.59 & $6.1(6)$ \\
\hline $9 \mathrm{~m} \mu$ & 58.91 & 21.57 & 43.44 & $9.4(9.3)$ & 46.59 & 24.59 & 52.01 & $8.9(8.7)$ \\
\hline
\end{tabular}

${ }^{a}$ Values in parentheses indicate $K / S$ after 10 washing cycles.

NP-printed fabrics gradually increased, giving a dark yellowish tone with an increase in the concentration of Ag-NPs, as shown by the positive high $b^{*}$ values. Furthermore, the lightness $\left(L^{*}\right)$ values gradually decreased for all the printed fabrics. This decrease in $L^{*}$ was a result of the coloration of the fabrics, which became deeper by increasing the concentrations of $\mathrm{Au}$ and $\mathrm{Ag}$ metal NPs.

The color strength $(K / S)$ data were measured at the wavelength of $425 \mathrm{~nm}$, which is related to the yellow color of Ag-NPs, whereas the wine-red color of Au-NPs was measured at the wavelength of $520 \mathrm{~nm}$. Fig. 6 shows that increasing the concentration of the synthesized Au-NPs and Ag-NPs resulted in a significant improvement in the color depth of the obtained metal $\mathrm{Au}$ and Ag NP prints expressed as the $K / S$ values. The observed data indicated that the darker yellow and red-wine colors of the printed fabrics were achieved by using higher concentrations of Au-NPs and Ag-NPs. This can be explained by the fact that a high number of spherical NPs were formed in the fabrics under investigation with the use of more concentrated Au-NP and Ag-NP colloidal solutions.

Moreover, the fabrics printed with Au-NPs had a red-wine color, and the fabrics printed with Ag-NPs had a yellow color

(a)

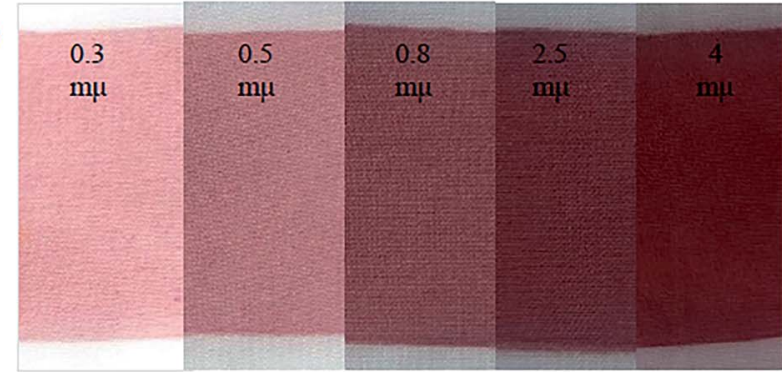

(b)

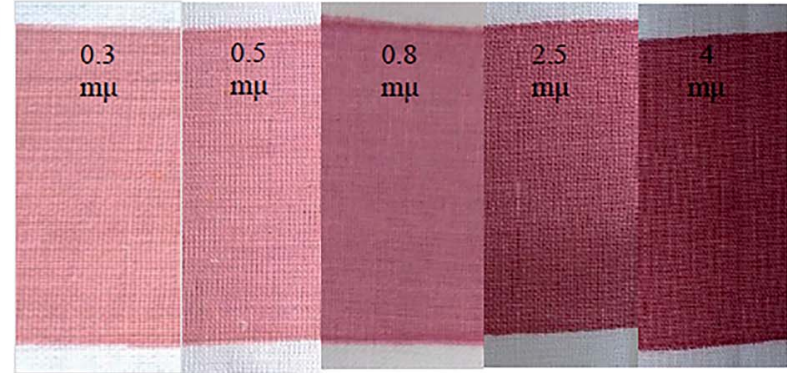

with different shades [from faint (red-wine/yellow) to dark (redwine/yellow)], but the nature of the color did not change regardless of the concentration of NPs. This may be regarded to the fact that the change in SPR of Au-NPs and Ag-NPs with different shapes and sizes on the polyester and cotton samples led to bright colors of the printed fabrics.

These results support the suggestion that cotton and polyester fabrics can be printed by synthesized silver and gold colloidal NPs as stable and fast colorants, and the color strength $(K / S)$ of these fabrics can be controlled by changing the concentration of synthesized Au-NPs and Ag-NPs.

\subsection{Fastness properties}

The coloration requirements are not limited to imparting color to the fabrics, but the acquired color should withstand the action of certain tests. Thus, different color fastness properties (washing, rubbing and light) of all the printed cotton and polyester fabrics were measured according to standard AATCC Test Methods (61-1972) and (8-1972), and (16A-1972), respectively, and the results are reported in Table 4 . The results showed that all the printed fabrics exhibited excellent fastness

(c)

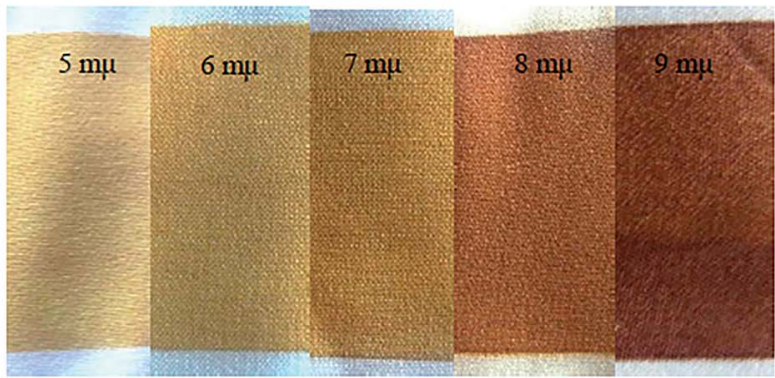

(d)

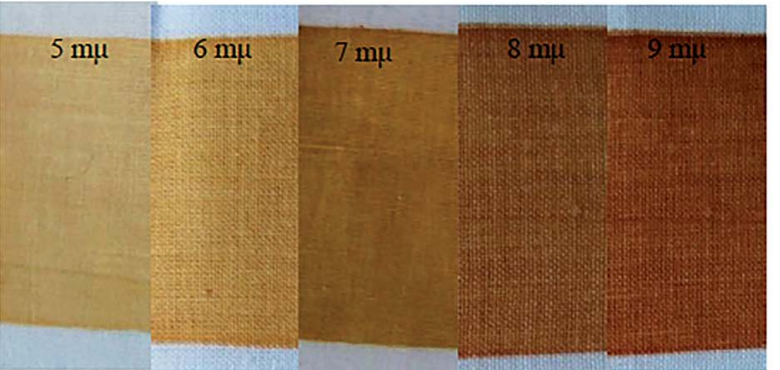

Fig. 5 Photographs of the metal NP-printed fabrics: (a) polyester/Au-NPs, (b) cotton fabrics with Au-NPs, (c) polyester fabrics with Ag-NPs, and (d) cotton fabrics with Ag-NPs. 


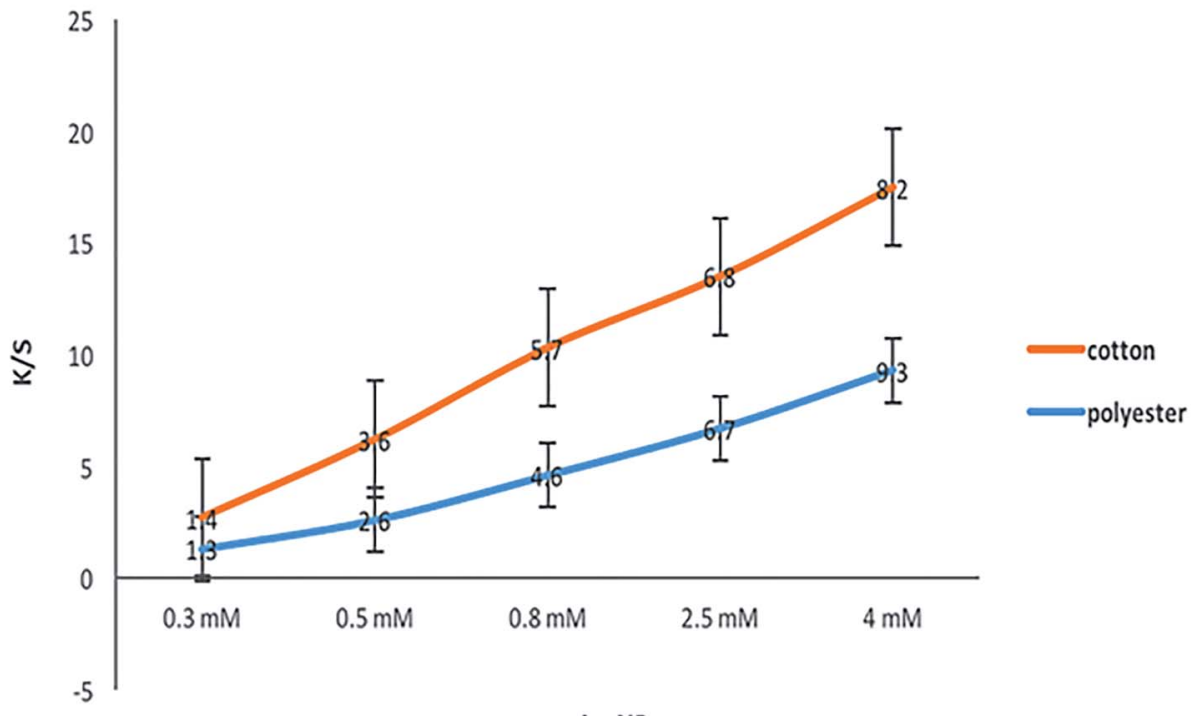

Au-NPs conc.

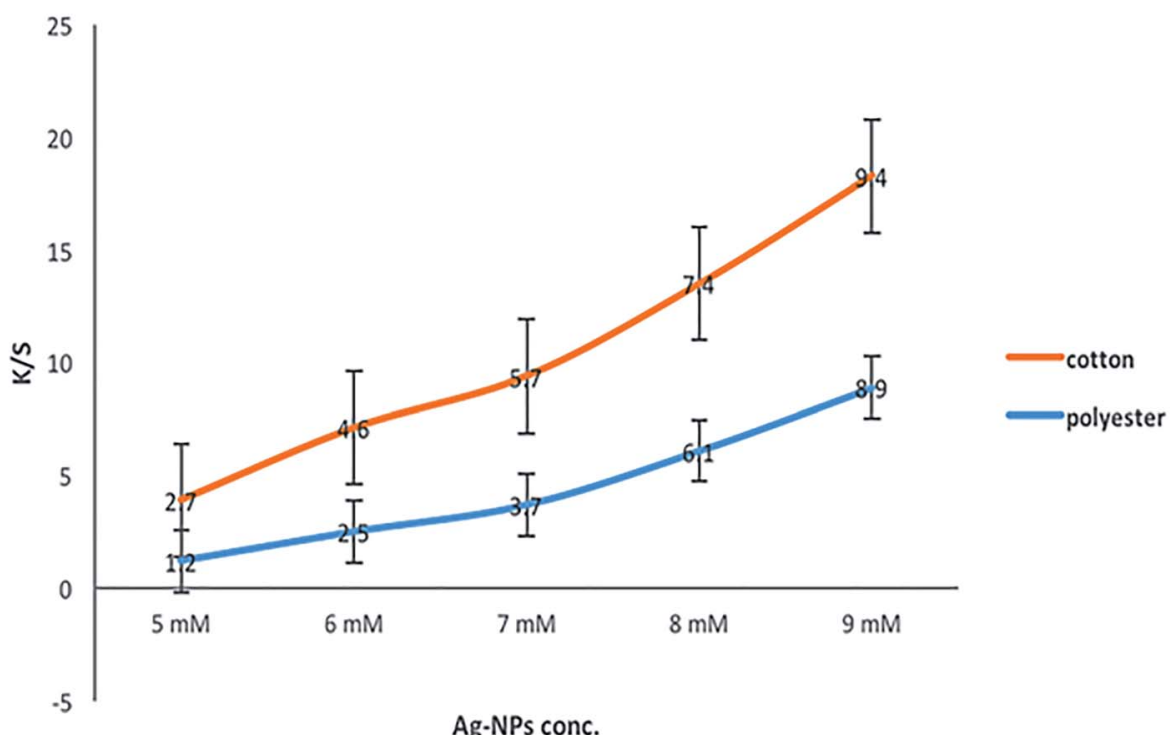

Fig. 6 Effect of metal NP concentration on $K / S$ of the printed fabrics.

levels to washing and rubbing and a very good fastness level to light. The obtained results reflected the ability of the suggested technique to yield good printed fabrics with excellent fastness properties without the use of any other chemicals (e.g., crosslinkers or coating materials).

\subsection{Antimicrobial activity}

The antimicrobial properties of the Au-NP- and Ag-NP-printed fabrics are shown in Table 5. The results revealed that the unprinted samples were not affected, and there were no inhibition areas. On the other hand, the cotton samples printed using $\mathrm{Ag}$ and Au-NPs as colorants exhibited excellent antimicrobial activities against $S$. aureus, Bacillus cereus, E. coli and Candida utilis. It is known that nano-materials have strong inhibiting effects towards a broad spectrum of bacteria and yeasts, especially those Ag-NPs displaying good activity against all the indicator pathogens, which shows the potential broad spectrum antimicrobial activity. ${ }^{45}$ The remarkable improvement

Table 4 Fastness properties of the metal NP-printed fabrics

\section{$\mathrm{WF}^{a} \quad \mathrm{RF}^{b}$}

\begin{tabular}{lllllll} 
Type of NPs & Type of fabric & St. & Alt. & Wet & Dry & LF $^{c}$ \\
\hline \multirow{2}{*}{ Control } & Polyester & - & - & - & - & - \\
& Cotton & - & - & - & - & - \\
Au-NPs & Polyester & 5 & 5 & $4 / 5$ & 5 & 4 \\
\multirow{3}{*}{ Ag-NPs } & Cotton & 5 & 5 & $4 / 5$ & 5 & $3 / 4$ \\
& Polyester & 5 & 5 & $4 / 5$ & 5 & $3 / 4$ \\
& Cotton & 5 & 5 & $4 / 5$ & 5 & 4
\end{tabular}

${ }^{a}$ Wash fastness. ${ }^{b}$ Rubbing fastness. ${ }^{c}$ Light fastness. 
Table 5 Antimicrobial activity of the metal NP-printed fabrics

\begin{tabular}{|c|c|c|c|c|c|}
\hline \multirow{2}{*}{ Type of NPs } & \multirow{2}{*}{ Type of fabric } & \multicolumn{4}{|c|}{ Antimicrobial activity $\mathrm{ZI}^{a}(\mathrm{~mm})$} \\
\hline & & \multicolumn{2}{|l|}{ G+ve } & $\frac{\mathrm{G}-\mathrm{ve}}{\text { E. coli }}$ & $\frac{\text { Yeast }}{\text { Candida utilis }}$ \\
\hline \multirow[t]{2}{*}{ Control } & Polyester & 0 & 0 & 0 & 0 \\
\hline & Cotton & 0 & 0 & 0 & 0 \\
\hline \multirow[t]{2}{*}{ Ag-NPs } & Polyester & 28 & 26 & 30 & 18 \\
\hline & Cotton & 24 & 28 & 18 & 20 \\
\hline
\end{tabular}

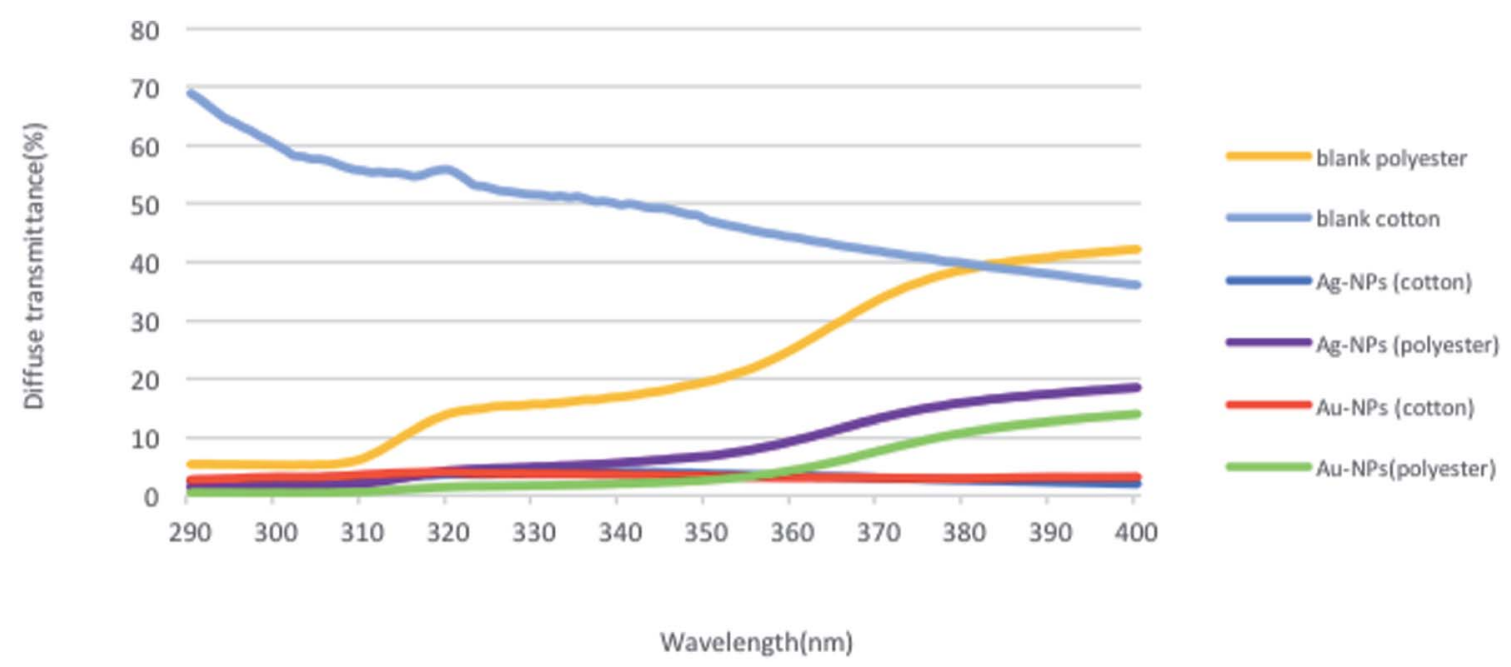

Fig. 7 Transmittance spectra of the blank and metal NP-printed fabrics.

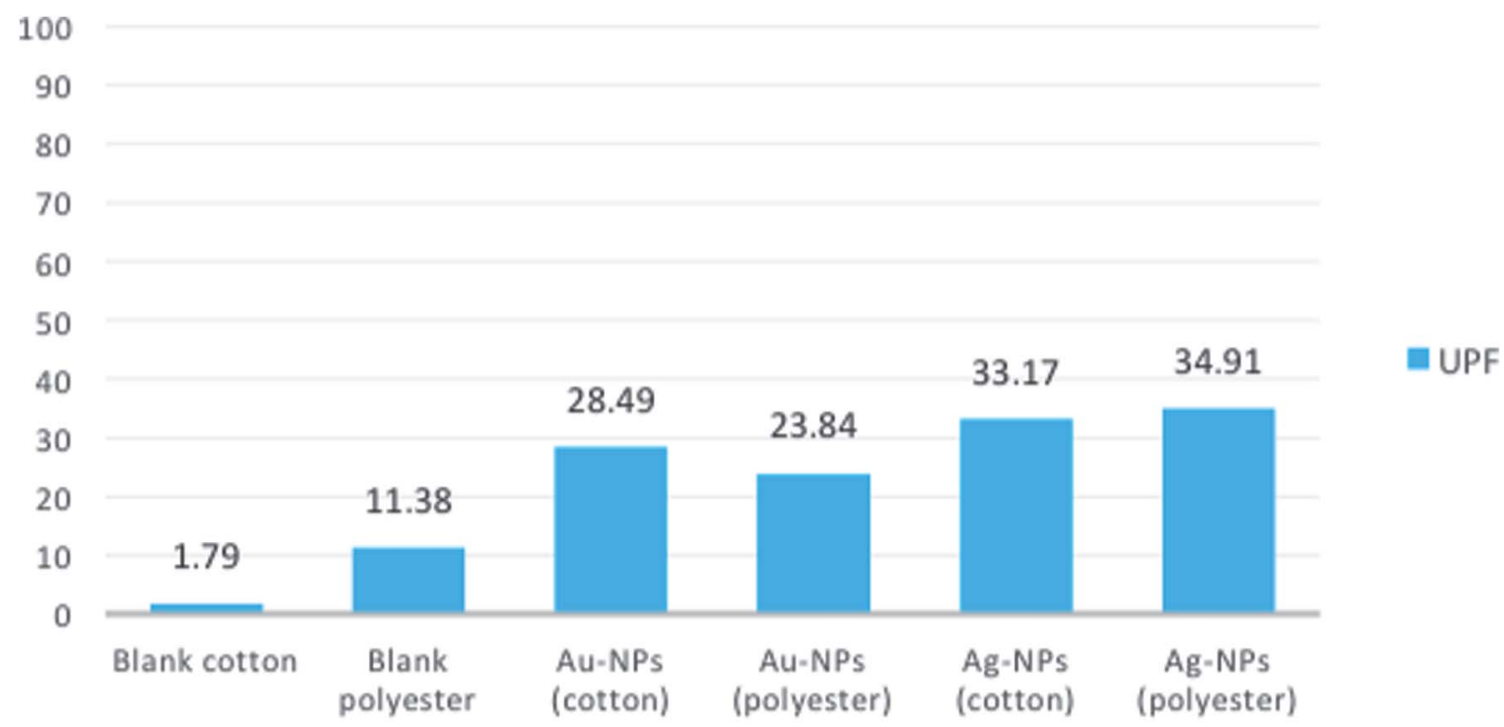

Fig. 8 UPF values of the blank and metal NP-printed fabrics.

in the antimicrobial functionality is ascribed to the interaction of the negatively charged cell walls of the pathogens with the positively charged cationic sites of the antimicrobial agent, which changes its chemical and physical properties. This action interrupts cell membrane functions and protein activity as well as the ability to multiply. In addition, the silver and gold 
Table 6 Durability of the imparted functional and color fastness properties after 10 washing cycles

\begin{tabular}{|c|c|c|c|c|c|c|c|c|c|c|c|}
\hline \multirow[b]{4}{*}{ Type of NPs } & \multirow[b]{4}{*}{ Type of fabric } & \multicolumn{5}{|c|}{ Fastness properties } & \multicolumn{5}{|c|}{ Functional properties } \\
\hline & & \multicolumn{2}{|c|}{$\mathrm{WF}^{a}$} & \multicolumn{2}{|l|}{$\mathrm{RF}^{b}$} & \multirow[b]{3}{*}{$\mathrm{LF}^{c}$} & \multicolumn{4}{|l|}{$\mathrm{ZI}^{d}(\mathrm{~mm})$} & \multirow[b]{3}{*}{ UPF } \\
\hline & & \multirow[b]{2}{*}{ St. } & \multirow[b]{2}{*}{ Alt. } & \multirow[b]{2}{*}{ Wet } & \multirow[b]{2}{*}{ Dry } & & \multicolumn{2}{|l|}{ G+ve } & \multirow{2}{*}{$\begin{array}{l}\mathrm{G}-\mathrm{ve} \\
E . \\
\text { coli }\end{array}$} & \multirow{2}{*}{$\begin{array}{l}\text { Yeast } \\
\begin{array}{l}\text { Candida } \\
\text { utilis }\end{array}\end{array}$} & \\
\hline & & & & & & & S. aureus & Bacillus Cereus & & & \\
\hline \multirow{3}{*}{ g-NPs } & Cotton & 5 & $4 / 5$ & $4 / 5$ & 5 & 4 & 16 & 20 & 14 & 12 & 26.87 \\
\hline & Polyester & 5 & $4 / 5$ & $4 / 5$ & 5 & 4 & 23 & 21 & 25 & 14 & 32.88 \\
\hline & Cotton & 5 & $4 / 5$ & $4 / 5$ & 5 & $4 / 5$ & 21 & 25 & 18 & 16 & 30.52 \\
\hline
\end{tabular}

${ }^{a}$ Wash fastness. ${ }^{b}$ Rubbing fastness. ${ }^{c}$ Light fastness. ${ }^{d}$ Zone of inhibition.

nanoparticles released silver and gold ions, which produced higher biocidal effect on the microorganisms. ${ }^{11,45}$

\subsection{UV-protection activity}

To investigate the UV-protection ability of the blank and polyester and cotton fabrics printed with Au-NPs and Ag-NPs, their UV light transmittance and UPF values were measured, and the results were illustrated in Fig. 7 and 8.

As expected, the blank samples are not good UV filters and a high percentage of UV light can penetrate into the fabric. However, the average transmittance values in the UVA (315-400 $\mathrm{nm}$ ) and UVB (280-315 $\mathrm{nm}$ ) regions for the fabrics decreased clearly after printing the fabrics with Au-NPs and Ag-NPs, which indicated that the gold and silver NPs noticeably improved the UV-blocking abilities of the polyester and cotton samples.

The UPF values of Au-NP- and Ag-NP-printed fabrics exhibit very good UV-protection according to the Australian classification scheme compared with those of blank fabrics, as shown in Fig. 8. Therefore, these results confirmed the UV reflection ability of Au-NPs and Ag-NPs, which can effectively decrease aging and reduce human skin damage caused by harmful UVradiation.

\subsection{Durability to washing}

The results illustrated in Table 6 reveal that the retention of the imparted functional properties, i.e., antimicrobial and UVprotection together with the fastness properties as well as the color strength $(K / S)$ of the obtained metal NPs prints was still high even after 10 washing cycles. This means that the metal NPs (Au-NPs and Ag-NPs) were still tightly loaded and fixed onto the simultaneously printed and finished fabric surfaces.

\section{Conclusion}

A facile and feasible strategy was devised to produce colorful and multifunctional printed polyester and cotton fabrics using synthesized NPs. This method featured the novelty of employing gold and silver NPs as eco-friendly stable colorants and functional components in a one-step process for printing and functional finishing of polyester and cotton fabrics. The results of the UV-visible, TEM, SEM and XRD measurements confirmed the successful synthesis and uniform distribution of spherical Au-NPs and Ag-NPs on polyester and cotton fabrics. The brilliant colored appearance, excellent color fastness properties, highly durable antibacterial activity and very good UV-protective properties of the nano-printed fabrics indicated their ability to produce good printed/finished fabrics in a one-step process without using traditional dyes or auxiliary chemicals.

\section{Conflicts of interest}

There are no conflicts to declare.

\section{References}

1 W. H. Solangi, Z. A. Noonari, A. A. Channa, M. Q. Khan and A. B. Siyal, Influence of Binders and Thickeners of Pigment Printing paste on Light Fastness and Crocking Fastness of the Fabric, Int. J. Sci. Res. Dev., 2014, 3, 1024-1032.

2 T. Feczko, K. Samu, K. Wenzel, B. Nerald and B. Voncina, Textiles screen-printed with photochromic ethyl cellulosespirooxazine composite nanoparticles, Color. Technol., 2013, 129, 18-23.

3 A. B. Rezaie, M. Montazer and M. M. Rad, A cleaner route for nano-colouration of wool fabric via green assembling of cupric oxide nanoparticles along with antibacterial and UV protection properties, J. Cleaner Prod., 2017, 221-231.

4 H. E. Emam and H. B. Ahmed, Carboxymethyl cellulose macromolecules as generator of anisotropic nanogold for catalytic performance, Int. J. Biol. Macromol., 2018, 111, 999-1009.

5 H. E. Emam, M. K. Zahran and H. B. Ahmed, Generation of biocompatible nanogold using $\mathrm{H}_{2} \mathrm{O}_{2}$-starch and their catalytic/antimicrobial activities, Eur. Polym. J., 2017, 90, 354-367; H. B. Ahmed, M. K. Zahran and H. E. Emam, Heatless synthesis of well dispersible $\mathrm{Au}$ nanoparticles using pectin biopolymer, Int. J. Biol. Macromol., 2016, 91, 208-219.

6 H. B. Ahmed, A. M. Abdel-Mohsen and H. E. Emam, Greenassisted tool for nanogold synthesis based on alginate as a biological macromolecule, RSC Adv., 2016, 6, 73974.

7 A. A. Hebeish, M. H El-Rafie, F. A. Abdel-Mohdy, E. S. AbdelHalim and H. E. Emam, Carboxymethyl cellulose for green 
synthesis and stabilization of silver nanoparticles, Carbohydr. Polym., 2010, 82, 933-941.

8 M. K. Zahran, H. B. Ahmed and M. H. El-Rafie, Facile sizeregulated synthesis of silver nanoparticles using pectin, Carbohydr. Polym., 2014, 111, 971-978.

9 M. K. Zahran, H. B. Ahmed and M. H. El-Rafie, Alginate mediate for synthesis controllable sized AgNPs, Carbohydr. Polym., 2014, 111, 10-17.

10 N. A. Ibrahim, B. M. Eid, E. Abd El-Aziz, T. M. Abou Elmaaty and S. M. Ramadan, Loading of Chitosan-Nano metal oxide hybrids onto cotton/polyester fabrics to impart permanent and effective multifunctions, Int. J. Biol. Macromol., 2017, 105, 769-776.

11 N. A. Ibrahim, B. M. Eid, E. Abd El-Aziz, T. M. Abou Elmaaty and S. M. Ramadan, Multifunctional cellulose-containing fabrics using modified finishing formulations, RSC Adv., 2017, 7, 3219-3230.

12 B. Tang, Y. Yao, J. Li, S. Qin, H. Zhu, J. Kaur, W. Chen, L. Sun and X. Wang, Functional Application of Noble Metal Nanoparticles in situ Synthesized on Ramie Fibers, Nanoscale Res. Lett., 2015, 10, 2-9.

13 X. Lin, F. Zou, X. Chen and B. Tang, Functional modification of Nylon fabrics based on noble metal nanoparticles, IOP Conf. Ser.: Mater. Sci. Eng., 2017, 231, 1-7.

14 S. Islam, B. S. Butola and F. Mohammad, Silver nanomaterials as future colorants and potential antimicrobial agents for natural and synthetic textile materials, RSC Adv., 2016, 6, 44232-44247.

$15 \mathrm{H}$. Oda, Improving Light Fastness of Natural Dye: Photostabilisation of Gardenia Blue, Color. Technol., 2012, 128, 68-73.

16 J. H. Johnston and K. A. Lucas, Nanogold synthesis in wool fibres: novel colourants, Gold Bull., 2011, 44, 85-89.

17 N. A. Ibahima, B. M. Eid, E. Abd El-Aziz and T. M. Abou Elmaaty, Functionalization of linen/cotton pigment prints using inorganic nano structure materials, Carbohydr. Polym., 2013, 97, 537-545.

18 N. A. Ibrahim, B. M. Eid, T. M. Abou Elmaaty and E. Abd ElAziz, A smart approach to add antibacterial functionality to cellulosic pigment prints, Carbohydr. Polym., 2013, 94, 612-618.

19 N. A. Ibrahim, T. M. Abou Elmaaty, B. M. Eid and E. Abd ElAziz, Combined antimicrobial finishing and pigment printing of cotton/polyester blends, Carbohydr. Polym., 2013, 95, 379-388.

20 N. A. Ibrahim, E. Abd El-Aziz, B. M. Eid and T. M. Abou Elmaaty, Single-stage process for bifunctionalization and eco-friendly pigment coloration of cellulosic fabrics, $J$. Text. Inst., 2015, 107, 1022-1029.

21 N. A. Ibrahim, B. M. Eid and M. S. Abdel-Aziz, Effect of plasma superficial treatments on antibacterial functionalization and coloration of cellulosic fabrics, Appl. Surf. Sci., 2017, 392, 1126-1133.

22 N. A. Ibrahim, B. M. Eid and M. S. Abdel-Aziz, Green Synthesis of AuNPs for Eco-friendly Functionalization of Cellulosic Substrates, Appl. Surf. Sci., 2016, 389, 118-125.
23 H. E. Emam and R. M. Abdelhameed, Anti-UV Radiation Textiles Designed by Embracing with Nano-MIL (Ti,In)Metal Organic Framework, ACS Appl. Mater. Interfaces, 2017, 9(33), 28034-28045.

24 H. B. Ahmed, H. E. Emam, H. M. Mashalyc and M. Rehan, Nanosilver leverage on reactive dyeing of cellulose fibers: color shading, color fastness and biocidal potentials, Carbohydr. Polym., 2018, 186, 310-320.

25 J. H. Johnston and K. A. Lucas, Nanogold synthesis in wool fibres: novel colourants, Gold Bull., 2011, 44, 85-89.

26 A. J. Kiyan, L. Karimi and A. Davodiroknabadi, Producing colored cotton fabrics with functional properties by combining silver nanoparticles with nano titanium dioxide, Cellulose, 2017, 24, 3083-3094.

27 S. Mowafi, M. Rehan, H. M. Mashaly, A. Abou El-Kheir and H. E. Emam, Influence of silver nanoparticles on the fabrics functions prepared by in- situ technique, J. Text. Inst., 2017, 108, 1828-1839.

28 H. E. Emam, M. Rehan, H. M. Mashaly and H. B. Ahmed, Large scaled strategy for natural/synthetic fabrics functionalization via immediate assembly of AgNPs, Dyes Pigm., 2016, 133, 173-183.

29 M. Rehan, H. M. Mashaly, S. Mowafi, A. Abou El-Kheir and H. E. Emam, Multi-functional textile design using in situ Ag NPs incorporation into natural fabric matrix, Dyes Pigm., 2015, 118, 9-17.

30 H. E. Emam, N. S. El-Hawary and H. B. Ahmed, Green technology for durable finishing of viscose fibers via selfformation of AuNPs, Int. J. Biol. Macromol., 2017, 96, 697705.

31 H. E. Emam, N. H. Saleh, K. S. Nagy and M. K. Zahran, Functionalization of medical cotton by direct incorporation of silver nanoparticles, Int. J. Biol. Macromol., 2015, 78, 249-256.

32 H. B. Ahmed, N. S. El-Hawary and H. E. Emam, Selfassembled AuNPs for ingrain pigmentation of silk fabrics with antibacterial potency, Int. J. Biol. Macromol., 2017, 105, 720-729.

33 T. V. Sreekumar, D. Arunashish, C. Lal, S. Anurage and R. K. Bhasker, Inherently colored antimicrobial fibers employing silver nanoparticles, J. Biomed. Nanotechnol., 2009, 5, 115-120.

34 S. Honary, P. Ebrahim and M. Ghsemitabar, Preparation of gold nanoparticles for biomedical applications using chemometric technique, Trop. J. Pharm. Res., 2013, 12, 295-298.

35 N. Azzaz, S. El-Kadi, K. S. Ahmed and M. Mahmoud, Antimicrobial Activities for Green Synthesis of Silver Nanoparticles using Stevia rebaudiana and Pluchea dioscoridis Leaves, International Journal of Agricultural and Biosystems Engineering, 2017, 2, 54-66.

36 H. N. Verma, P. Singh and R. M. Chavan, Gold nanoparticle: synthesis and characterization, Vet. World, 2014, 7, 72-77.

37 H. E. Emam, S. Mowafi, H. M. Mashaly and M. Rehan, Production of antibacterial colored viscose fibers using in situ prepared spherical Ag nanoparticles, Carbohydr. Polym., 2014, 110, 148-155. 
38 S. Al-Azad, M. N. Morshed, H. Deb, M. A. Alam, K. M. F. Hasan and X. Shen, Localized Surface Plasmon Resonance Property of Ag-Nanoparticles and Prospects as Imminent Multi-Functional Colorant, American Journal of Nanoscience and Nanotechnology Research, 2017, 5, 2-20.

39 A. R. Prado, J. P. Oliveira, W. J. Keijok, B. A. Milaneze, B. V. Nogueira, M. C. Guimarães, M. J. Pontes and M. R. Ribeiro, Comparison between the synthesis of gold nanoparticles with sodium citrate and sodium tetraborate, BMC Proc., 2014, 8, 252.

40 K. Alaqad and T. Saleh, Gold and Silver Nanoparticles: Synthesis Methods, Characterization Routes and Applications towards Drugs, Journal of Environmental and Analytical Toxicology, 2016, 6, 1-10.

41 C. Krishnaraj, E. G. Jagan, S. Rajasekar, P. Selvakumar, P. Kalaichelvan and N. Mohan, Synthesis of silver nanoparticles using Acalypha indica leaf extracts and its antibacterial activity against water borne pathogens, Colloids Surf., B, 2010, 76, 50-56.

42 A. M. Abdelghany, A. H. Oraby, A. A. Hindi, D. M. El-Nagar and F. S. Alhakami, Green synthesis of mixed metallic nanoparticles using room temperature self-assembly, $J$. Adv. Phys., 2017, 13, 4671-4676.

43 K. Anandalakshmi and J. Venugobal, Green Synthesis and Characterization of Silver Nanoparticles Using Vitex negundo (Karu Nochchi) Leaf Extract and its Antibacterial Activity, Med. Chem., 2017, 7, 218-225.

44 M. Chelladurai, R. Shanmugam, V. Mahendran, P. Kanniah, G. Gnanadhas and A. Gurusamy, Eco-friendly synthesis and characterization of gold nanoparticles using Klebsiella pneumonia, J. Nanostruct. Chem., 2013, 3, 1-7.

45 N. Gokarneshan and K. Velumani, Application of Nano Silver Particles on Textile Materials for Improvement of Antibacterial Finishes, Glob. J. Nanomed., 2017, 2, 1-4. 